\title{
Medios de comunicación y publicidad privada: Comentarios desde los estándares internacionales de derechos humanos
}

\section{Media and private advertising: Comments from international human rights standards}

\section{Federico Aguirre Madrid}

Pontificia Universidad Católica de Valparaíso

famc3@hotmail.com

Juan Pablo González Jansana

Universidad Diego Portales

juanpablo.gonzalezj@mail.udp.cl

\section{Resumen}

A la luz de los estándares internacionales de derechos humanos relacionados con libertad de expresión y de derechos humanos y empresa, y en el contexto de la concentración de la propiedad de los medios de comunicación en Chile, los autores analizan los resultados del estudio sobre medios de comunicación y publicidad privada en el caso sobre colusión en los precios de medicamentos por parte de las cadenas de farmacias.

Palabras claves: Libertad de expresión, concentración de medios de comunicación, farmacias, derechos humanos.

\begin{abstract}
Through international standards on human rights related with freedom of speech and human rights and companies, and in the context of the Chilean concentration on media property, the authors develop an analysis of the results of the study about media and private advertising in the case of the collusion of drugstores in the prices of medicaments.
\end{abstract}

Keywords: Freedom of speech, media concentration, drugstores, human rights. 


\section{Introducción}

Existe una tensión en la relación entre medios de comunicación, publicidad y democracia, que para los derechos humanos es de especial interés. Los medios de comunicación constituyen instituciones fundamentales en una democracia, al cumplir un rol informador hacia la ciudadanía y de fiscalización al poder estatal. Son estos los que transmiten y difunden información de interés público vital para los procesos de toma de decisiones individuales o colectivos. Por lo mismo, los organismos de derechos humanos, como la Relatoría Especial para la Libertad de Expresión, han hecho especial hincapié en la obligación del Estado de asegurar las condiciones necesarias para que los medios y los periodistas actúen de manera independiente, libre y autónoma, ajenos a toda presión, directa o indirecta, que pueda afectar ilegítimamente su ejercicio.

No obstante lo anterior, los medios de comunicación no son entes abstractos ajenos a la realidad nacional, sino que, por el contrario, también se ven moldeados por la sociedad en que se desenvuelven. En este sentido, la tensión entre medios de comunicación, publicidad y democracia encuentra su punto más rígido cuando el medio se enfrenta a la disyuntiva de informar ciertos hechos que implicarían una merma en la publicidad y, por tanto, poner en riesgo la estabilidad económica del medio.

¿Cómo informar un hecho de interés público cuando está involucrada una empresa que publicita sus servicios en ese medio? ¿Es una afectación a la libertad de expresión atenuar la manera de informar (o simplemente no informar) con el objeto de evitar problemas con los avisadores del medio? ¿Existen obligaciones desde los derechos humanos para el Estado y para los medios de comunicación en estos hechos? Estas son solo algunas de las preguntas que forman parte de la tensión aludida y que motivan el presente artículo.

Esta tensión, además, se encuentra enmarcada en Chile, en un escenario con una fuerte propiedad en los medios de comunicación por parte de dos empresas, sin una política pública integral que fomente el pluralismo informativo, lo que deja en manos de los medios del oligopolio la construcción de un discurso informativo que crea realidad y sentido común.

El presente artículo propone un análisis a partir del estudio "Publicidad privada y sus implicancias para el ejercicio del periodismo y las libertades de expresión y de prensa en Chile” desde los estándares internacionales en derechos humanos, en especial de aquellos en materia de libertad de expresión y de derechos humanos y empresas. Estos estándares encuentran su fuente en los tratados internacionales que el Estado de Chile ha firmado y ratificado, como también en la interpretación oficial que los organismos de derechos humanos han hecho de tales tratados.

Así, en una primera parte, hacemos un resumen de los estándares más relevantes para el caso, para posteriormente, en una segunda parte, analizar el caso de la colusión de farmacias desde estos estándares con énfasis en dos cuestiones principales: (i) el contexto, dado por la concentración en los medios de comunicación en Chile y cómo podría haber afectado la 
manera de cubrir el caso y (ii) un análisis específico del caso desde una perspectiva de derechos humanos y cómo eso afecta no solo el derecho a la libre expresión. Finalmente, proponemos algunas conclusiones.

\section{Estándares internacionales de derechos humanos}

\section{Libertad de Expresión}

Uno de los derechos que más ha trabajado tanto la Corte Interamericana como la Comisión Interamericana de Derechos Humanos (Corte IDH y Comisión IDH, respectivamente) en su jurisprudencia, es la libertad de expresión. Para estos órganos, este derecho es un pilar dentro de una sociedad democrática e implica un conjunto de obligaciones para el Estado.

Estos estándares han puesto atención al rol que cumplen los medios de comunicación social en una democracia. Así, la Corte IDH ha planteado que "son los medios de comunicación social los que sirven para materializar el ejercicio de la libertad de expresión, de tal modo que sus condiciones de funcionamiento deben adecuarse a los requerimientos de esa libertad. Para ello es indispensable, inter alia, la pluralidad de medios, la prohibición de todo monopolio respecto de ellos, cualquiera sea la forma que pretenda adoptar, y la garantía de protección a la libertad e independencia de los periodistas"1.

Específicamente, la Corte IDH ha remarcado la relevancia de los medios en la doble dimensión de la libertad de expresión, es decir, en el derecho de toda persona a expresarse y a conocer la opinión ajena. Así lo expresó la Corte IDH al plantear que "ésta [la libertad de expresión] requiere, por un lado, que nadie sea arbitrariamente menoscabado o impedido de manifestar su propio pensamiento y representa, por tanto, un derecho de cada individuo; pero implica también, por otro lado, un derecho colectivo a recibir cualquier información y a conocer la expresión del pensamiento ajeno"2. Por lo mismo, "los medios de comunicación social juegan un rol esencial como vehículos para el ejercicio de la dimensión social de la libertad de expresión en una sociedad democrática, razón por la cual es indispensable que recojan las más diversas informaciones y opiniones. Los referidos medios, como instrumentos esenciales de la libertad de pensamiento y de expresión, deben ejercer con responsabilidad la función social que desarrollan”3.

\footnotetext{
1 Corte IDH. Opinión Consultiva 5/85 sobre Colegiación obligatoria de periodistas. 13 de noviembre de 1985, párr. 34.

2 Corte IDH. Opinión Consultiva 5/85 sobre Colegiación obligatoria de periodistas. 13 de noviembre de 1985, párr. 30.

3 Corte IDH. Sentencia caso Herrera Ulloa vs. Costa Rica. 2 de julio de 2004, párr. 117.
} 
Para cumplir con este fin, el Estado debe asegurar que ningún medio sea objeto de medios directos o indirectos de censura previa. Sobre estos últimos, el artículo 13.3 de la $\mathrm{CADH}$ señala expresamente que "no se puede restringir el derecho de expresión por vías o medios indirectos, tales como el abuso de controles oficiales o particulares de papel para periódicos, de frecuencias radioeléctricas, o de enseres y aparatos usados en la difusión de información o por cualesquiera otros medios encaminados a impedir la comunicación y la circulación de ideas y opiniones". La Relatoría Especial para la Libertad de Expresión de la OEA (la Relatoría) en su Informe Anual 2004 define estas violaciones indirectas como aquellas que:

"no han sido diseñadas estrictamente para restringir la libertad de expresión. En efecto, éstas per se no configuran una violación de este derecho. No obstante ello, sus efectos generan un impacto adverso en la libre circulación de ideas que con frecuencia es poco investigado y, por ende, más difícil de descubrir” (2004, p. 130).

Los medios indirectos de censura a medios de comunicación no son taxativos ni únicamente pueden provenir del Estado. Como se señalaba, el artículo 13 hace referencia a "todo medio encaminado a impedir la comunicación o la circulación de ideas y opiniones”, por lo que tiene una fórmula abierta a los cambios sociales que se van produciendo en toda sociedad, donde las formas para censurar van variando. Asimismo, entender la complejidad de las comunicaciones conlleva a comprender que si bien los casos típicos de censura indirecta tienen al Estado como ente censurador (no entrega arbitraria de frecuencias radiofónicas o manipulación de la publicidad oficial), la realidad ha mostrado también cómo particulares pueden ejecutar actos de censura indirecta, por ejemplo, concentrar la propiedad de los medios de comunicación o condicionar el apoyo financiero a un medio de comunicación según cómo este informe.

Lo anterior no significa, desde una perspectiva de derechos humanos, que el Estado no tenga responsabilidad: por el contrario, su obligación de garantía de derechos fundamentales implica necesariamente el deber de adoptar todas las medidas necesarias para que los medios puedan operar de manera libre y autónoma a toda presión. Tal como ha planteado la Corte IDH, la responsabilidad internacional del Estado "puede generarse por actos u omisiones de cualquier poder u órgano de éste, independientemente de su jerarquía, que violen la Convención Americana [sobre Derechos Humanos]. Es decir, todo acto u omisión, imputable al Estado, en violación de las normas del Derecho Internacional de los Derechos Humanos, compromete la responsabilidad internacional del Estado"4. Asimismo, también ha señalado la Corte IDH que " $[\mathrm{u}] \mathrm{n}$ hecho ilícito violatorio de los derechos humanos que inicialmente no resulte imputable directamente a un Estado, por ejemplo, por ser obra de un particular o por no haberse identificado al autor de la trasgresión, puede acarrear la responsabilidad internacional

4 Corte IDH. Sentencia caso "La Última Tentación de Cristo" (Olmedo Bustos y otros) vs. Chile. 5 de febrero de 2001, párr. 72. 
del Estado, no por ese hecho en sí mismo, sino por falta de la debida diligencia para prevenir la violación o para tratarla en los términos requeridos por la Convención [Americana sobre Derechos Humanos]"s.

Desde la doble dimensión de la libertad de expresión, la presión o cualquier injerencia ilegítima por parte de privados a medios de comunicación constituye una afectación del derecho a la libre expresión no solo del medio de comunicación, quien se ve obstaculizado en su capacidad para informar, sino que también es una afectación a la dimensión social de la libertad de expresión, ya que la ciudadanía ve obstaculizado su derecho a informarse a través de los medios de comunicación.

En este sentido la Relatoría ha señalado que:

"los medios de comunicación permiten que los individuos puedan formar su propia opinión política y luego comparar la suya con la de otros. Solamente cuando el individuo es informado podrá evaluar y libremente adherirse a una u otra postura dentro del espectro político. Precisamente, la necesidad de mayor información, junto a la libertad para poder expresar e intercambiar opiniones, tienen una vital importancia en los procesos de toma de decisiones en los que los distintos miembros de la sociedad participan. El ejercicio de la libertad de expresión por parte de los ciudadanos de un Estado depende directamente de que los medios de comunicación provean información de manera libre e independiente" (2004, p. 132).

La información empodera, permite a la ciudadanía fiscalizar, controlar a las autoridades, como también es parte fundamental para la autodeterminación de las personas y los pueblos en sus procesos de toma de decisiones. Por lo mismo, el Estado no debe estar ajeno a los obstáculos que impiden a los medios de comunicación funcionar adecuadamente, ya que esos obstáculos necesariamente implican una afectación de la dimensión social de la expresión. Así lo ha manifestado la Corte IDH al señalar que "las dos dimensiones $[\ldots]$ de la libertad de expresión deben ser garantizadas simultáneamente. No sería lícito invocar el derecho de la sociedad a estar informada verazmente para fundamentar un régimen de censura previa supuestamente destinado a eliminar las informaciones que serían falsas a criterio del censor. Como tampoco sería admisible que, sobre la base del derecho a difundir informaciones e ideas, se constituyeran monopolios públicos o privados sobre los medios de comunicación para intentar moldear la opinión pública según un solo punto de vista”.6.

Ahora bien, el análisis de los medios de comunicación desde una perspectiva de derechos humanos, conlleva a comprender que el medio como tal es una empresa informativa y, en

5 Corte IDH. Sentencia caso Velásquez Rodríguez vs. Honduras (Fondo). 29 de julio de 1988, párr. 172.

6 Corte IDH. Opinión Consultiva 5/85 sobre Colegiación obligatoria de periodistas. 13 de noviembre de 1985, párr. 33. 
ese sentido, se debe buscar si las reglas del mercado generan incentivos perversos que se traducen en violaciones indirectas a la libertad de expresión. Desde hace unos años, el derecho internacional de los derechos humanos ha estudiado la relación entre empresas y derechos humanos, entendiendo que los entes privados no están ajenos a cumplir con estos, sino que de su funcionamiento diario depende el ejercicio de derechos fundamentales.

2. Las empresas como sujetos no estatales con obligaciones en derechos humanos

En el derecho internacional de los derechos humanos el principal responsable por la satisfacción de las obligaciones de respeto, garantía y protección de los derechos humanos es el Estado. Ello es así, desde que la construcción del marco normativo internacional ha girado en torno a este sujeto de derecho internacional, en una doble faz, como fuente y como destinatario de estas normas.

Ello, sin embargo, no significa que los agentes no estatales sean indiferentes a esta área del derecho. Los Estados, en cumplimiento de sus obligaciones internacionales en estas materias, deberán, respecto de los actos u omisiones de particulares y agentes no estatales, desplegar y proveer una institucionalidad pública capaz de prohibir, erradicar y, en su caso, reparar y sancionar hechos que importen una amenaza o lesión a derechos fundamentales.

Sin embargo, a pesar de la claridad de a las obligaciones del Estado en estas materias, no sucede lo mismo en relación a la imputabilidad de responsabilidad directa por parte de los sujetos empresariales y agentes no estatales en hechos que importen una infracción a los derechos humanos. Ello no obstante que en el contexto de una comunidad globalizada, de mercados altamente concentrados y economías abiertas, la actividad de estos actores eventualmente entraña externalidades negativas que entran en tensión con el disfrute y goce plenos de los derechos humanos.

La comunidad internacional, consciente de esta realidad ha perfilado en el último tiempo incipientes estándares de naturaleza programática (normas de Soft Law), destinadas a estos sujetos. Una de sus expresiones más significativas son los Principios Rectores sobre las empresas y los derechos humanos: Puesta en práctica del marco de las Naciones Unidas para "Proteger, respetar y remediar", sistematizados por el ex Representante Especial del Secretario General de Naciones Unidas para la cuestión de los derechos humanos y las empresas transnacionales y otras empresas, John Ruggie 7 .

7 Ver John Ruggie. Informe del representante especial del Secretario General para la cuestión de los derechos humanos y las empresas transnacionales y otras empresas. Principios rectores sobre las empresas y los derechos humanos: puesta en práctica del marco de las Naciones Unidas para "proteger, respetar y remediar". Asamblea General. A/HRC/17/31. 21 de marzo de 2011. 
En ellos se establecen deberes complementarios del Estado y las empresas, constituyendo la obligación principal del Estado el ofrecer protección respecto a la actividad de agentes no estatales, y la de estas el respetar los derechos humanos bajo el estándar de la debida diligencia, lo que supone por parte de ambos actores la obligación de diseñar políticas corporativas capaces de identificar, prevenir y abordar los impactos que el ejercicio de su actividad tiene sobre los derechos humanos. Por último, los Principios reclaman un marco de garantías compartidas entre el ente estatal y empresarial, de acceso a formas de justiciablidad y reparación de derechos conculcados con motivo de la acción de agentes no estatales. Estos Principios representan el consenso que se ha logrado obtener en el marco de las Naciones Unidas y han sido recogidos entre otras instancias por la Organización Internacional de Normalización -ISO - la que en 2010 publicó la norma de responsabilidad social ISO 26000 y por la Organización de Cooperación y Desarrollo Económicos (OCDE) cuyas Directrices para las empresas multinacionales fueron actualizadas el 2011, la que asienta el principio de respeto de los derechos humanos tal cual se definen en los Principios Rectores.

La discusión ha ido de la mano de crecientes procesos de repliegue del Estado a favor del sector privado en ámbitos sociales sensibles vinculados, entre otros, a los sectores de salud, educación, seguridad social, energía y recursos naturales, sistemas carcelarios y vivienda, por señalar solo algunos. De esta manera, en la agenda de derechos humanos se ha instalado la necesidad de abordar esta realidad, en la que así " [c] omo antes era necesario limitar los poderes de los Estados, hoy día es necesario limitar los poderes y las facultades de las grandes empresas, puesto que ellas, sobre todo las multinacionales, ahora desafían la dominación económica y política tradicional de los Estados" (International Council on Human Rights Policy, 2002, p. 9).

Estos esfuerzos normativos por extender la eficacia de los derechos humanos a los entes no estatales $-\mathrm{y}$, por lo tanto, a la actividad privada-, entran en tensión con modelos de desarrollo asentados en la máxima, política y económica, de que al Estado solo le cabe un rol subsidiario, relegando su acción a la satisfacción de aquello que el mundo privado no sea capaz o no quiera satisfacer. En esta concepción, la libertad comercial y la protección a la iniciativa privada representan principios cardinales elevados en nuestro país por el constituyente de 1980 a garantías fundamentales. Un ejemplo de este diseño institucional se da en relación a la concentración de los medios de comunicación, su impacto en el derecho a la libertad de expresión y la manipulación que eventualmente pueda significar este fenómeno en la deliberación democrática.

\section{El caso en estudio}

Tal como se señalara en un inicio, nos parece adecuado organizar los comentarios en dos materias. Por una parte, la relación entre la concentración en la propiedad de los medios de 
comunicación con el caso bajo análisis y, posteriormente, aspectos específicos del caso a la luz de los estándares internacionales ya mencionados en el acápite anterior.

1. La concentración en la propiedad de los medios de comunicación

El estudio hace mención a este aspecto, señalando específicamente que la concentración tiene tres dimensiones: propiedad, participación en el mercado de las audiencias y la participación en el mercado publicitario. Tal como ha señalado recientemente el Instituto Nacional de Derechos Humanos (INDH):

"la existencia de medios de comunicación autónomos y pluralistas en una democracia es un aspecto fundamental, ya que inciden en el debate público, informan a la sociedad, y pueden interpelar a las autoridades. En este sentido, la existencia de una concentración en la propiedad de los medios de comunicación social [e]s un aspecto preocupante en Chile” (2012, p. 320).

Esta concentración en la propiedad se refleja fuertemente en los medios de prensa escrita (Anguita, 2005). No es una novedad señalar la existencia de un oligopolio, donde, por una parte, se encuentra El Mercurio S.A.P., empresa informativa que tiene la propiedad de un conjunto de medios nacionales y regionales a lo largo del país y, por otra, el Grupo Copesa (Consorcio Periodístico de Chile S.A.), dueño de medios de circulación nacional y algunos a nivel regional. Cabe agregar que ambos conglomerados se han expandido a otros sectores comunicacionales, como el radial.

Esta concentración es, también, ideológica. En este sentido, compartimos la postura de Couso (2012) al plantear que "en Chile los dueños de la prensa escrita comparten un marcado sesgo ideológico que hace muy difícil que otras perspectivas tengan presencia en este ámbito tan crucial para la definición y características de la agenda pública nacional” (2012, p. 125). A modo de ejemplo, el gerente general de El Mercurio, Jonny Kulka, ha planteado que este medio "está casado con lo que es su ideario que promueve la propiedad privada, el respeto a la economía, el libre mercado, respetar los medios de producción, que los recursos sean bien asignados [y] el rol subsidiario del Estado” (2009, p. 32). Esto se traduce en que la ciudadanía recibe mayoritariamente una mirada de la noticia desde una postura específica, que no tiene grandes diferencias entre ambas empresas, con un discurso que construye una realidad común.

Este oligopolio conlleva necesariamente a una fuerte presencia en el mercado, sin mayor competencia debida a las barreras de entrada y sin un Estado que haya adoptado desde la recuperación de la democracia medidas efectivas para asegurar el pluralismo informativo. Por lo mismo, no debe sorprender la concentración de la publicidad, tanto privada como oficial, por parte de estas empresas. La constatación de este hecho es relevante para el caso bajo análisis, toda vez que los medios que se estudiaron integran, sin excepción, estos conglomerados. Por 
una parte, La Tercera y La Cuarta forman parte del Grupo Copesa, mientras que El Mercurio, LUN, El Mercurio de Valparaíso, El Sur de Concepción y El Austral de Temuco forman parte del holding de empresas de El Mercurio.

Si bien el caso de estudio concluye que no se puede presumir que los avisadores determinaron el contenido de la prensa analizada, nos parece interesante detenernos en algunos detalles que no son menores. El primero de ellos -y que por el momento solo mencionamos, ya que nos referiremos a él en detalle más adelante- radica en que difícilmente un caso de la notoriedad pública como el de la colusión de las farmacias no iba a ser informado por los medios de comunicación. Esto, principalmente, porque la noticia no se origina en los medios de comunicación, sino que estalla a partir de la denuncia de la Fiscalía Nacional Económica (FNE), tal como especifica el Hito 1 del estudio.

En segundo lugar, los efectos de la concentración no deben medirse únicamente en si un hecho es o no informado, sino que también es relevante cómo ese hecho es informado. Un medio de comunicación no es un ente abstracto, sino que escribe desde una trinchera, desde una determinada línea editorial, en una sociedad determinada. Por lo tanto, lo informado por un medio es, realmente, cómo lee un hecho o un conjunto de hechos a partir de su apuesta editorial. Obviamente la línea editorial no justifica tergiversar la información ni transgredir el deber de rigurosidad de todo medio, pero siempre existirá una lectura del hecho donde adquiere relevancia que la audiencia conozca desde qué trinchera un medio está informando. Tal como señala el estudio, las noticias nos dicen qué y cómo pensar.

En línea con lo anterior, el estudio sí entrega algunos detalles importantes. Por ejemplo, la mayoría de las notas informativas sobre la colusión no mencionan a las farmacias ni en el titular ni en la bajada. Así, de las 529 portadas estudiadas, 420 no nombran a las farmacias involucradas (en 238 portadas no son nombradas y en 182 se habla genéricamente de "farmacias"). Cuestión similar en la bajada de la noticia. De 279 bajo análisis, en 114 no se nombran a las farmacias involucradas y en 74 se habla genéricamente de "farmacias". Asimismo, según el estudio, de las 530 noticias analizadas, 454 se encontraban en una nota interior y no en la portada del medio ni en la portada de la sección. Si bien estas cifras no son sustento para conclusiones más potentes, sí deben tenerse en cuenta para analizar cómo los medios informan los hechos y cómo su relato crea realidad en un contexto de concentración en la propiedad de estos. A lo anterior, cabe agregar que la prensa escrita determina la agenda noticiosa, por lo tanto, qué y cómo informan, en un escenario de bajo pluralismo informativo, debe ser motivo de alerta en una sociedad democrática.

En tercer lugar, la escasa cobertura que hacen los medios analizados del Hito 3 del estudio, es decir, la huelga de los trabajadores de Farmacias Ahumada, es también un llamado de alerta. Tal como expresa el editor de uno de los medios nacionales entrevistado por el estudio, "la huelga es invisible, porque los trabajadores son invisibles, porque los medios chilenos promueven una línea editorial pro-empresa, pro emprendimiento, pro negocios, donde el sindicalismo y los derechos y/o temáticas laborales quedan excluidas". 
A la luz de los estándares internacionales de derechos humanos, este es un hecho de máxima gravedad, en el sentido de que la concentración en la propiedad de los medios se traduce, consecuentemente, en la inexistencia o invisibilidad de medios con perspectiva de derechos humanos -como los derechos laborales-, o en que informen hechos noticiosos tan relevantes como el de la colusión sin esta perspectiva. El deber del Estado al respecto no es restringir ilegítimamente el derecho de El Mercurio o La Tercera a la libertad de prensa, sino que adoptar todas las medidas necesarias para fomentar el pluralismo informativo, donde la ciudadanía en virtud de la doble dimensión de la libertad de expresión-, tenga acceso a medios que dan prioridad a la libertad económica y medios que relevan los derechos humanos como parte del debate público. Tal como señala Fiss, en oportunidades como esta:

"el Estado puede verse obligado a actuar para promover el debate público: cuando poderes de carácter no estatal ahogan la expresión de opiniones. Habrá de asignar recursos públicos $[\ldots]$ a aquellos cuyas voces de otra forma no serían oídas en la plaza pública” (1999, p. 14).

2. Colusión, medios de comunicación y derecho a la información

El hecho público y notorio en el que se apoya parte del estudio que se comenta, esto es, la colusión farmacéutica para encarecer artificialmente el precio de ciertos medicamentos y el impacto que ello pudiera acarrear en la forma de informar este hecho a la opinión pública por parte de los principales medios de comunicación escrita, es otro ejemplo de las tensiones que la actividad empresarial puede acarrear en materia de disfrute y goce de los derechos fundamentales, sobre todo de sectores de la población más vulnerados y carenciados.

La garantía de acceso a los medicamentos es concebida como un componente fundamental del deber de garantizar progresivamente el derecho a la salud. De esta manera, el imponer barreras de acceso a medicamentos entraña un atentado o lesión a un derecho humano entendido, a la luz del artículo 12 del Pacto Internacional de Derechos Económicos, Sociales y Culturales como "[e]l derecho de toda persona al disfrute del más alto nivel posible de salud física y mental [...]”. Más aún cuando el ejercicio de este derecho se relaciona con el derecho a la vida y la integridad física y psíquica de la persona.

Lo que se demostró por parte de la Fiscalía Nacional Económica, y que fue acogido por el Tribunal de Defensa de la Libre Competencia y posteriormente por la Corte Suprema, es que las tres principales cadenas farmacéuticas del país (Farmacias Ahumada, SalcoBrand y Cruz Verde), que concentran el 90\% del mercado nacional de distribución de medicamentos, entre diciembre de 2007 y marzo de 2008 se coludieron para alterar el precio de 206 fármacos, calificados de notorios y éticos, es decir, no susceptibles de ser fácilmente reemplazados por el o la paciente y donde algunos de ellos están destinados a ofrecer terapia farmacológica a 
enfermedades crónicas ${ }^{8}$. Ello representa a la luz de los fallos dictados, un atentado a la libre competencia y una distorsión del mercado. Por ello han sido sancionadas.

Desde la perspectiva de los derechos humanos, este acto constituye una lesión a la garantía de acceso al derecho a la salud de la población, que tuvo por un único norte, por parte de estas cadenas de farmacias, redituar a corto plazo beneficios económicos a costa de la salud de los individuos.

El hecho en sí mismo, el acto delictual develado y finalmente sancionado, es un hecho imposible de no ser objeto de cobertura por parte de los medios de comunicación. Representa un hecho noticioso público y notorio, difícilmente no visible ante la ciudadanía o evitado de ser informado y comentado. Se trata ni más ni menos que de un acto abusivo por parte de las más importantes empresas distribuidoras de fármacos que especulan y obtienen ganancias respecto de bienes esenciales para sectores de la población que padecen alguna dolencia o enfermedad. En este sentido $-\mathrm{y}$ tal como ya hemos señalado-, el problema no es que no se informe, sino cómo se informa.

Asimismo, es plausible plantear el cuestionamiento a los medios de comunicación en su rol fiscalizador. Esto porque, en general, respecto de los casos de alta connotación pública, estos han nacido de investigaciones judiciales, fiscalizaciones administrativas o denuncias de la sociedad civil, pero son pocos los casos en que los medios pertenecientes al oligopolio informativo denuncian un hecho en particular. Por el contrario, el estudio bajo análisis muestra cómo los medios descansan preferentemente en fuentes oficiales, sin poner en duda o sospecha tales fuentes ni su veracidad.

Las mismas empresas coludidas son adicionalmente importantes avisadores de los principales medios de comunicación escritos. De esta manera, la hipótesis que las y los investigadores se plantean, en orden a advertir la eventual colisión de intereses entre cadenas proveedoras de recursos vía aviso publicitario y empresas de comunicación, responde a una legítima duda en torno a la independencia que dichos medios de comunicación pueden detentar frente a poderosos actores económicos, que son quienes sustentan financieramente la viabilidad de la empresa de comunicación, los que por añadidura en el mercado nacional se encuentran altamente concentrados.

En este sentido, resultaría interesante un estudio de las mismas características y metodología en relación a un conjunto de hechos donde se encontrara en juego la misma tensión, pero sin el mismo impacto público. En definitiva, en un caso como este, no informar la colusión era una abierta afectación a la doble dimensión de la libertad de expresión y al derecho a la información de la ciudadanía, difícilmente justificable. Sin embargo, tensiones de estas características están presentes a diario en los medios de comunicación y son escenario de decisiones editoriales complejas donde los medios se juegan su credibilidad.

8 Tribunal de Defensa de la Libre Competencia, ROL C N ${ }^{\circ}$ 184-08. Sentencia núm. 119/2012, de 31 de enero de 2012, considerando quincuagésimo sexto. Sentencia confirmada por la Corte Suprema, Rol N ${ }^{\circ} 2578-2012$ de 7 de septiembre de 2012 . 
Desde la perspectiva del derecho internacional de los derechos humanos, hemos visto que las empresas, incluidas las de carácter periodístico, tienen el deber de respetar los derechos humanos y actuar con la debida diligencia y el Estado el de garantizarlos y protegerlos. El punto en análisis es también reflexionar cómo el Estado, en este marco, desempeña su rol de garante en relación a la libertad de expresión, que como ha sido señalado, está íntimamente vinculado a la vigencia y fortalecimiento de la convivencia democrática.

\section{Conclusiones}

En toda sociedad democrática los medios de comunicación cumplen un rol fundamental. Son ellos quienes fiscalizan al Estado y a privados, informan a la sociedad sobre hechos de interés público y participan en el establecimiento de la agenda pública. En este sentido, el Estado tiene la obligación de fortalecer y garantizar condiciones elementales para que los medios de comunicación puedan desempeñarse libre y autónomamente, sin estar sujetos a presiones directas ni indirectas por parte ni de agentes estatales ni privados.

Sin embargo, en su funcionamiento se ven enfrentados a una serie de presiones en razón que no son entes autónomos alejados de la sociedad, sino que deben subsistir en ella y ofrecer información a la ciudadanía. Es en esa disyuntiva, donde la publicidad privada, pilar para la mantención económica de un medio, puede operar como mecanismo de censura indirecta para el medio, no solo por afectar la libertad de prensa del medio, sino que también porque eso conlleva necesariamente a la afectación del derecho de la ciudadanía a acceder a la información.

Así, si bien en el caso estudiado se concluye que pese a la inversión que las farmacias realizaban en los medios, estos se mantuvieron informando sobre la colusión, la notoriedad pública del caso deja ciertas sospechas sobre si ante casos de menor notoriedad, pero donde los medios están expuestos ante la misma tensión, el resultado sería el mismo.

Queda la inquietud planteada en un país donde urge una política pública que fomente el pluralismo informativo y donde la sociedad tenga acceso a más fuentes de información, concretando así la profundización de nuestra democracia. 


\section{Referencias bibliográficas}

Anguita, P. (2005). El derecho a la información en Chile. Análisis de la Ley 19.733 sobre libertades de opinión e información y ejercicio del periodismo.

Couso, J. (2012). El Mercado como obstáculo a la libertad de expresión: La concentración de la prensa escrita en Chile en la era democrática. En B. Sorj, Democracia y medios de comunicación. Más allá del estado y el mercado (pp. 109-142). Buenos Aires: Konrad Adenauer Stiftung.

Fiss, O. (1999). La ironía de la libertad de expresión. Barcelona: Gedisa.

Instituto Nacional de Derechos Humanos. (2012). Informe Anual 2012. Situación de los Derechos Humanos en Chile. Santiago.

International Council on Human Rights. (2002). Beyond Voluntarism. Human Rights and the developing international legal obligations of companies. Versoix.

Lagos, C. (Ed.). (2009). El Diario de Agustín. Santiago: LOM Ediciones.

Relatoría Especial para la Libertad de Expresión. (2004). Informe Anual 2004. Washington DC. 